\title{
Idealism and Scepticism: A Reply to Brueckner
}

\author{
by \\ STEPHEN PURYEAR \\ North Carolina State University
}

Abstract: Anthony Brueckner argues that Berkeleyan idealism lacks anti-sceptical force because of the way Berkeley draws the appearance/reality distinction. But Brueckner's case rests on a misunderstanding of Berkeley's view. Properly understood, Berkeleyan idealism does indeed have anti-sceptical force.

Keywords: Idealism, Scepticism, Appearance, Reality, Berkeley

Cartesian theories of perception, on which we perceive external objects only by perceiving or grasping the corresponding ideas in our minds, open the door to scepticism about the external world by making it difficult if not impossible for us to know whether our ideas truly correspond to any external reality. Descartes himself proposed a clever fix for this problem. On his view, we can be sure that the external world exists at least as we clearly and distinctly perceive it because we can demonstrate that a supremely perfect being exists and that this being is not a deceiver. Unfortunately for Descartes, this sort of roundabout theological approach to dodging scepticism never gained much traction.

Berkeley famously advocated a simpler, more direct approach. He argued that we can truly remove the threat of scepticism only by closing the gap between our ideas of objects and the objects themselves. This can be accomplished in one of two ways, either by eliminating ideas and allowing for a direct perception of external objects, or by eliminating external objects and treating ideas as the real things. But being firmly convinced that the only things we immediately grasp or perceive are ideas, Berkeley dismissed the first of these options and embraced the second. Thus his idealism.

In a recent contribution to this journal, Anthony Brueckner argues that the Berkeleyan strategy fails. The problem, according to Brueckner, stems from Berkeley's account of the difference between those ideas which count as real things, such as my idea of the Eiffel Tower, and those which rank as chimeras, such as my idea of a golden mountain. On this account, the former ideas differ from the latter in virtue of having the property of "intra-mind and inter-mind experiential coherence" (Brueckner, 2011, p. 369). That is, ideas that count as real things cohere with the other ideas in one's mind as well as the ideas in the minds of others, whereas imaginary ideas lack one or both of these kinds of coherence. Given this criterion of reality, however, a new sceptical challenge arises. For it is not clear how one could ever be sure that one's own ideas cohere with those of others. If I have an experience as of a purple rat on the table in front of me, Brueckner argues, then it is possible that other minds are also having (or are disposed to have) a similar experience. In that case, my purple-rat-experience would count as veridical and the purple rat would be real. But for all I know, I may be the only one having (or disposed to have) such an experience, and in that case my experience would be illusory. Thus, despite initial appearances to the contrary, Berkeley's idealism fails to avoid the sceptical threat after all. 
Though otherwise sound, I believe this analysis rests on a misunderstanding of Berkeley's criterion of reality. In short, though Berkeley clearly considered intra-mind coherence to be a necessary condition of the reality of ideas, there is little if any reason to think he considered inter-mind coherence to be such a condition. Let us look at what he himself says on the subject. His fullest consideration of the matter comes in sections 30-36 of the Treatise Concerning the Principles of Human Knowledge. There he asserts that in order for an idea to qualify as real, it must be sufficiently "strong", "lively", "vivid", "distinct", and "affecting". More to the point, it must also be sufficiently "steady", "orderly", and "coherent" (Berkeley, 1710, ss. 30, 33, 36). ${ }^{1}$ What sort of coherence does he have in mind? Unfortunately there are few clues. Immediately after mentioning coherence, he does point out that real ideas are "not excited at random ... but in a regular train or series, the admirable connection whereof sufficiently testifies [to] the wisdom and benevolence of its author" (ibid., s. 30). Similarly, a few sections later he says that ideas of sense are impressed upon the perceiver "according to certain rules or laws of nature" (ibid., s. 36). But these comments have to do with intra-mind coherence - coherence in the train of ideas within a given mind - and nothing Berkeley says in these passages suggests that inter-mind coherence plays a role in his criterion of reality.

Berkeley revisits the issue in the Three Dialogues Between Hylas and Philonous. In response to a question from Hylas about the difference between real and imaginary things (ideas), Philonous remarks that though the visions of a dream may be lively and natural, they can easily be distinguished from realities by virtue of "their not being connected and of a piece with the preceding and subsequent transactions of our lives" (Berkeley, 1713, pp. 68-69). In other words, intra-mind coherence is a necessary condition of reality. But as in the previous discussion from the Principles, one finds not even a whiff of the idea that inter-mind coherence is also required for reality.

The only Berkeleyan text I am aware of in which we find any mention of the idea of intermind coherence appears later in the Principles. In response to an objection about the reality of miracles, Berkeley remarks:

To this I reply that the rod was changed into a real serpent, and the water into real wine. That this does not in the least contradict what I have elsewhere said will be evident from Sections 34 and 35 . But this business of real and imaginary has been already so plainly and fully explained, and so often referred to, and the difficulties about it are so easily answered from what has gone before, that it were an affront to the reader's understanding to resume the explication of it in this place. I shall only observe that if at table all who were present should see, and smell, and taste, and drink wine, and find the effects of it, with me there could be no doubt of its reality .... (Berkeley, 1710, s. 84, emphasis added)

Here Berkeley is indeed talking about inter-mind coherence, but notice that he offers it only as a sufficient and not a necessary condition of recognizing something as real. If my idea coheres with the ideas of those in my vicinity, he claims, then my experience is surely veridical. But it does not follow that I must be aware of this sort of coherence in order to have this assurance.

${ }^{1}$ For Berkeley these qualities are more than just marks of reality; they are constitutive of reality. This is clear from sections 34 and 36 of the Principles, where he emphasizes that on his view, to be real means nothing other than to have these qualities. 
Berkeley clearly believes that intra-mind coherence is required in order for an experience to count as veridical. But nowhere in his writings do we find any clear indication that inter-mind coherence is also required. It would therefore be reasonable to suppose that on his view only the former sort of coherence is required for veridicality. But if that be so, then the sceptical challenge posed by Brueckner falls by the wayside. If I am having a purple-rat-experience, then I can be sure that this experience is veridical just by reflecting on whether it is sufficiently vivid, distinct, etc., and also whether it coheres with my other experiences. And since for Berkeley these are matters about which I could not possibly be wrong, there is no danger that my experience is illusory.

In a footnote, Brueckner considers precisely the view I have just ascribed to Berkeley, but rejects it on the ground that it "requires the existence of a sort of multiverse, in which there is a purple rat in my room now in one 'branch', while there is no purple rat in my room now in other branches, the one's lacking purple-rat-in-Brueckner's-room experience" (Brueckner, 2011, p. 370, n. 7). To this I would say two things. First, it is far from clear that this sort of multiverse is really problematic. Consider the parallel case of the seemingly banal view that colors exist only in the mind. It could be objected that this view requires a sort of multiverse in which colors exist in some branches but not others. For example, if a rat appears purple to me but gray to everyone else, then the purple of that rat would exist in the branch of the "multiverse" corresponding to my mind but not in any of the other branches. But what exactly is the difficulty with such a view? I confess to finding none. Second and moreover, even if this were a cogent objection to the view I am attributing to Berkeley, it does not follow that it was not his view.

Some versions of idealism may indeed require inter-mind experiential coherence in order for an experience to qualify as veridical; and Brueckner is quite right that such versions of idealism do not offer any special advantages with respect to avoiding scepticism. But when it comes to Berkeleyan idealism, the target of Brueckner's critique, matters are otherwise. For Berkeley, the qualities that render one's experience veridical are all internal to one's own mind and thus there can be no doubt whether one's experiences possess these qualities. Contrary to what Brueckner suggests, the Berkeleyan idealist does seem to be at an advantage when it comes to defeating scepticism.

\section{References}

Berkeley, G (1710) A Treatise Concerning the Principles of Human Knowledge. Cited by section number from K. Winkler, ed. (1982) A Treatise Concerning the Principles of Human Knowledge. Indianapolis: Hackett Publishing Company.

Berkeley, G. (1713) Three Dialogues Between Hylas and Philonous. Cited by page number from R. Adams, ed. (1979) Three Dialogues Between Hylas and Philonous. Indianapolis: Hackett Publishing Company.

Brueckner, A. (2011) "Idealism and Scepticism." Theoria, 77: 368-71. 